\title{
An Automatic System for Continuous Monitoring and Sampling of Groundwater Geochemistry in Earthquake-Prone Regions of SW Taiwan
}

OPEN ACCESS

Edited by: Guodong Zheng,

Chinese Academy of Sciences (CAS),

China

Reviewed by:

Tianming Huang,

Chinese Academy of Sciences (CAS),

China

Ying Li,

China Earthquake Administration

China

*Correspondence:

Ching-Chou Fu

ccfu@earth.sinica.edu.tw

${ }^{\dagger}$ Deceased

Specialty section: This article was submitted to Geochemistry,

a section of the journal

Frontiers in Earth Science

Received: 30 November 2020

Accepted: 25 January 2021

Published: 25 February 2021

Citation:

Fu C-C, Lai C-W, Yang TF, Hilton DR,

Chen $\mathrm{C}-\mathrm{H}$, Walia V, Kumar $\mathrm{A}$ and Lee L-C (2021) An Automatic System

for Continuous Monitoring and

Sampling of Groundwater Geochemistry in Earthquake-Prone

Regions of SW Taiwan.

Front. Earth Sci. 9:635913.

doi: 10.3389/feart.2021.635913

\begin{abstract}
Ching-Chou Fu ${ }^{1 *}$, Chun-Wei Lai ${ }^{2}$, Tsanyao Frank Yang ${ }^{2 \dagger}$, David R. Hilton ${ }^{3+}$, Cheng-Hong Chen ${ }^{2}$, Vivek Walia ${ }^{4}$, Arvind Kumar ${ }^{4}$ and Lou-Chuang Lee ${ }^{1}$

${ }^{1}$ Institute of Earth Sciences, Academia Sinica, Taipei, Taiwan, ${ }^{2}$ Department of Geosciences, National Taiwan University, Taipei, Taiwan, ${ }^{3}$ University of California, San Diego, La Jolla, CA, United States, ${ }^{4}$ National Center for Research on Earthquake

Engineering, NARL, Taipei, Taiwan
\end{abstract}

Previous studies have revealed that gas compositions of fluid samples collected from southwestern Taiwan, where many hot springs and mud volcanoes are distributed along with tectonic structures, show significant variation before and after some disaster seismic events. Such variations, including radon activity, $\mathrm{CH}_{4} / \mathrm{CO}_{2}$, and ${ }^{3} \mathrm{He} /{ }^{4} \mathrm{He}$ ratios of gas compositions, are considered precursors of earthquakes in this area. An automatic system for continuous on-line gas monitoring and groundwater sampling was established at YunShui (YS), where an artesian well located at an active fault zone in SW Taiwan, to validate the relationship between fluid compositions and seismicity. It is equipped with a quadrupole mass spectrometer (QMS) and a radon detector for in-situ measurement of the dissolved gas composition. Variations of dissolved gas compositions are transmitted to the laboratory through the internet. Furthermore, a syringe pump apparatus for the retrieval and temporal analysis of helium (SPARTAH) is also installed for off-line laboratory analysis for obtaining the detailed time-series records of helium, hydrogen, oxygen, and dissolved inorganic carbon (DIC) isotopic compositions as well as dissolved inorganic carbon and chloride concentration of water samples at this station. After continuous monitoring for several months, two substantial anomalies of multiparameter were observed prior to the significant earthquakes. This automated system has been demonstrated to be feasible for long-term continuous seismo-geochemical research in this area.

Keywords: on-line gas monitoring, syringe pump apparatus for the retrieval and temporal analysis of helium, off-line laboratory analysis, multiparameter, seismo-geochemical research

\section{INTRODUCTION}

Since the 1970s, geochemical studies have been carried in the world for earthquake precursors (Sugisaki, 1978; O’Neil and King, 1981; Sugisaki, and Sugiura, 1985; Roeloff, 1988). Precursory anomalies in the radon concentration of groundwater were reported before the Izu-Oshima-kinkai earthquake in 1978 and the Kobe earthquake in 1995 (Wakita et al., 1980; Igarashi et al., 1995). 
Hydrogeochemical changes, including stable isotopes and noble gas isotopes, were observed before and after the large earthquakes in Iceland and Japan (Sano et al., 1998; Sano et al., 2016; Skelton et al., 2014; Onda et al., 2018). Preseismic changes in groundwater level and temperature were detected from the well before the 1970 M6.7 Przhevalsk Earthquake and the 2011 Tohoku Earthquake (Sadovsky et al., 1972; Orihara et al., 2014). Change in several water parameters is proposed as the precursory signals, particularly groundwater chemistry, water temperature, water level, and radon concentration, have also been reported before the earthquakes in many geological environments in Taiwan, such as hot/cold springs, mud volcanoes, and groundwater well (Liu et al., 1985; Chia et al., 2001; Wang, C. H. et al., 2001; Wang, C. Y. et al., 2001; Song et al., 2003; Song et al., 2005; Song et al., 2006; Yang et al., 2004; Yang et al., 2006; Kuo et al., 2006; Yuo et al., 2010; Lai et al., 2010; Chen et al., 2013).

It is worthy to note that the distribution of many mud volcanoes and hot springs are along with the tectonic structures in southwestern Taiwan, indicating that the fluids and gases may migrate through the fault zones to provide information regarding the deep sources (Yang et al., 2004; Chao et al., 2010; Chao et al., 2011; Chao et al., 2013; Sun et al., 2010; Sano et al., 2017). Regular sampling of radon in water had been performed for earthquake prediction since 1980 in Taiwan, showing $\mathrm{Rn}$ anomalies correlated with earthquakes (Liu et al., 1985). Song et al. (2006) concluded that hydrochemical variations of $\mathrm{Cl}^{-}$and $\mathrm{SO}_{4}{ }^{2-}$ concentrations at the Kuan-tze-ling (KTL) hot spring increased a few days before the Chi-Chi earthquake through the biweekly sampling. Song et al. (2003) collected commercially bottled groundwater around the epicenter for investigating changes in groundwater composition and found the obvious increase of $\mathrm{SO}_{4}{ }^{2-}$ and $\mathrm{NO}_{3}{ }^{-}$concentrations before the Chi-Chi earthquake. Similarly, Sano et al. (2020) reported oxygen isotope anomalies before the Kumamoto earthquake by analyzing groundwater samples from the packaged drinking bottle collected from a deep well located $3 \mathrm{~km}$ to the epicenter. Yang et al. (2006) have continuously monitored the gas composition of the Chunglun (CL) mud pool along the Chukou Fault (CKF), and proposed $\mathrm{CO}_{2} / \mathrm{CH}_{4}$ variations in bubbling gases were sensitive to the earthquake events. The significant temporal changes of the ${ }^{3} \mathrm{He} /{ }^{4} \mathrm{He}$ ratio in bubbling gas were detected before and after the 1999 Chi-Chi earthquake (Fu and Lee, 2018). It suggests that the $\mathrm{CL}$ area is very susceptible to seismic activity. However, the biweekly or monthly sampling interval was performed based on on-site manual sampling. Yet, some short-term precursory anomalies may not be caught due to the low sampling frequency.

Due to many years of research and improvement, the real-time analysis of gas compositions has been quite mature for studying and monitoring the earthquake precursors (Yang et al., 2006; Weinlich, 2014; Ono et al., 2020). In contrast, precise measurements of chemical concentrations and isotopic ratios in water are difficult presently, and mass-spectrometers cannot be installed directly on the field to carry out continuous monitoring. Hence, there is a lack of understanding of the fluid's geochemical behaviors to produce consecutively anomalous changes. In this paper, we test an automatic sampling system for water samples, which is named the
Syringe Pump Apparatus for the Retrieval and Temporal Analysis of Helium (SPARTAH) designed by Barry et al. (2009). The SPARTAH can continuously and precisely sample the fluids and analyze them in the laboratory later.

Gas compositions are dominated with $75-90 \%$ of $\mathrm{CO}_{2}$ and $5-12 \%$ of $\mathrm{CH}_{4}$ together with the higher ${ }^{3} \mathrm{He} /{ }^{4} \mathrm{He}$ value of $5.9 \mathrm{Ra}$ at $\mathrm{CL}$, suggesting that they might be originated from a deep source with a magmatic signal; meanwhile, major constituents of gases are $82-95 \%$ of $\mathrm{CH}_{4}$ and $2-15 \%$ of $\mathrm{CO}_{2}$ with a lower ${ }^{3} \mathrm{He} /{ }^{4} \mathrm{He}$ value of $<0.4 \mathrm{Ra}$ at KTL area, indicating a deep crust source (Yang et al., 2004; Yang, 2008). However, the fluids at the CL and KTL sites are too muddy to perform the SPARTAH system. An artisan well at Yunshui (YS) close to the major fault near the CL site is then selected for this experiment. Dissolved gas samples from the YS site are dominated with $\mathrm{CH}_{4} \sim 96 \%$ and associated with $\mathrm{C}_{2} \mathrm{H}_{6}$ $\sim 0.3 \%$, which is similar to nearby mud volcano gases, which are typical thermogenic gas derived from crustal source with low helium isotopic ratios (<0.4 Ra) (Yang et al., 2004; Yang, 2008). It suggests that the YS site may have opportunities to detect gas and fluid geochemical anomalies related to the generation of earthquakes migrating from crustal source upward subsurface along the fault. Fluids of YS are mixed between two different reservoirs from CL and KTL is also likely to have occurred. This paper aims to describe the characteristics of the on-line monitoring system and off-line laboratory analysis and assess the feasibility of using the SPARTAH system to obtain high resolutions and precise measurements of different geochemical parameters in water for earthquake precursory studies in Taiwan.

\section{GEOLOGICAL BACKGROUND}

Taiwan is located on the boundary between the Eurasian plate and Philippine Sea plate with a convergence rate of $\sim 80 \mathrm{~mm} / \mathrm{yr}$ by the northwestward movement (Yu et al., 1997), a series of subparallel ENE-WSW trending reverse faults and folds developed from east to west in Taiwan (Lin et al., 2000). The target of this study is the Chiayi-Tainan area in southwestern Taiwan (Figure 1). There are three major faults, the Muchiliao Fault (MCLF), the Chukou Fault (CKF), and the Lunhou Fault (LHF), cutting through this area in a NE-SW trend based on field geological survey, drilling core, Seismic Reflection profiles, and ground resistivity (Shih et al., 2003; Lin et al., 2007). The MCLF is a reverse-slip fault along the Liushuang (Ls) Formation (brownish-yellow sandstone with thick mudstone) and can be identified on the western border of Chiayi hills. Although it might have been reactivated during the Late Quaternary, there is a lack of outcrops and evidence to support its existence. The CKF is a high-angle thrust $\sim 40-60^{\circ}$ with a fault plane dipping to the east, dividing from the Miocene to the Pleistocene in the study area.

Stratigraphy in the vicinity of the study area can be classified into several units from east to west, which are the Miocene Tangenshan Sandstone (Tn) Formation (thick-bedded massive sandstone and muddy sandstone), the Miocene Chunlun (Cl) Formation (shale, sandy shale and mudstone), the Pliocene Niaotsui (Nt) Formation (muddy sandstone, sandy shale and thick-bedded sandstone), the Pliocene Yunshuichi (Ys) Formation (shale and sandy shale and 


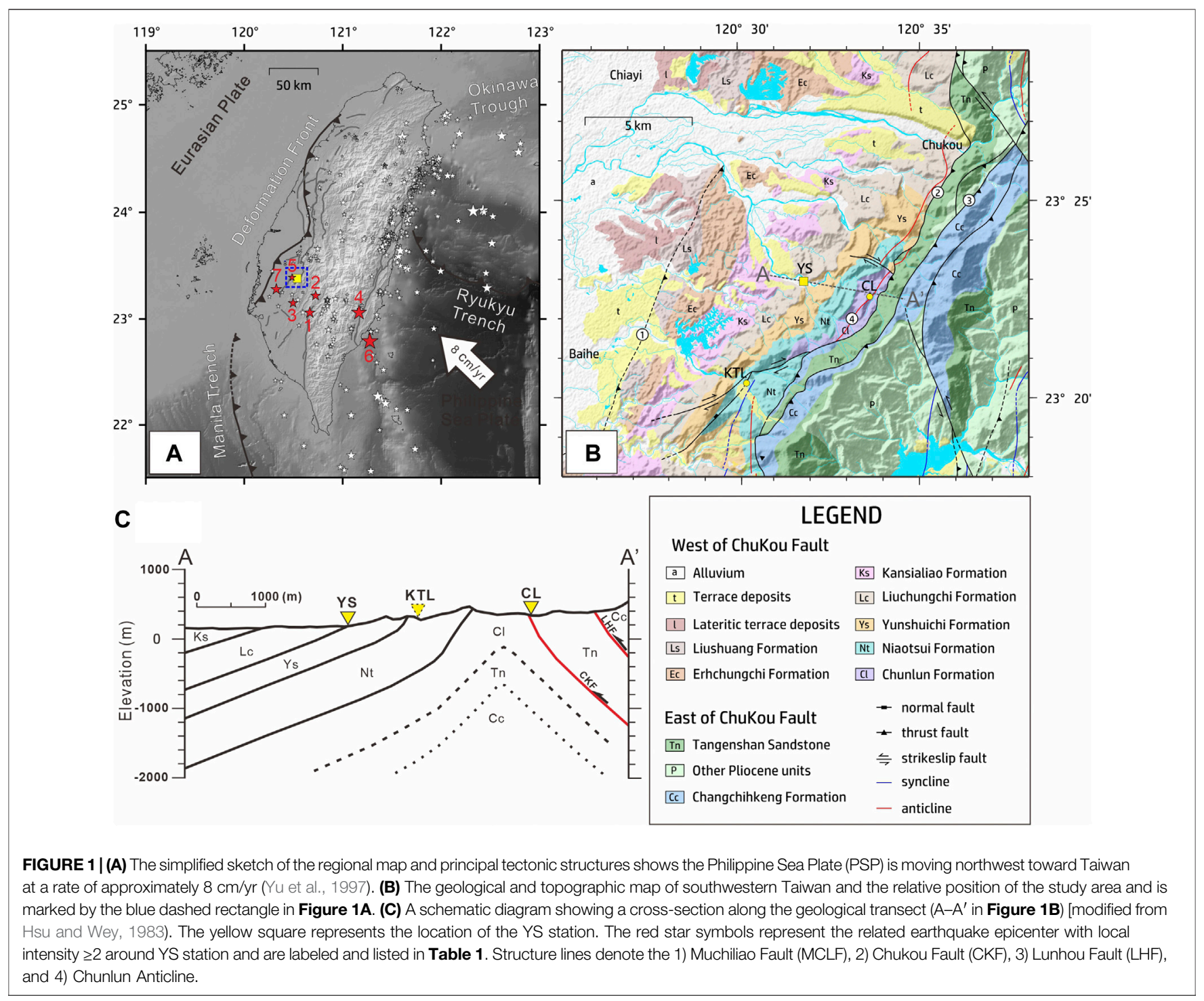

mudstone), and the Pleistocene Liuchungchi (Lc) Formation (siltstone with shale, sandy shale or interbedded with muddy sandstone). The LHF is another thrust fault with a strike-slip component dipping to the southeast. It separates the Miocene Changchikeng $(\mathrm{Cc})$ Formation (sandstone, sandstone interbedded with shale) from the Tn Formation. Based on GPS data by Yu and Chen (1998), a significant horizontal velocity of $6.3-13 \mathrm{~mm} / \mathrm{yr}$ and strain rate of $0.48-2.01 \mu$ strain/yr near the CKF can be observed. Otherwise, the seismicity around the LHF area is not active, but it has a very high horizontal velocity of $14.7 \mathrm{~mm} / \mathrm{yr}$ (Hung et al., 1999). The CKF-LHF system exhibits an evident creep phenomenon, implying that the crustal stress accumulation is fast in this area and a substantial potential for the generation of the great earthquake.

The observation YS well is approximately $100 \mathrm{~m}$ deep. Except for the yellowish-brown weathered soil layer near the surface, the rock core from YS well mainly comprises gray muddy fine sandstone with thin-bedded shale or fine sandstone from 6 to $100 \mathrm{~m}$ depth. A more permeable aquifer at a depth of $97-98 \mathrm{~m}$ where thick fine sandstone was penetrated to install a screen for monitoring purposes in the Ys Formation. The CL mud pool is located on the culmination of the Chunlun anticline about $3 \mathrm{~km}$ east of the YS site, whereas the KTL hot spring locates approximately $7 \mathrm{~km}$ south of the YS site in the $\mathrm{Nt}$ formation. Fluid materials of CL and KTL might contribute deeper than the $\mathrm{Cl}$ formation and the $\mathrm{Nt}$ formation, respectively (Figures 1B,C).

\section{METHODOLOGY}

The monitoring station was set up at YS site to analyze and determine the composition of dissolved gases and geochemistry of water extracted from an artesian well with a low-flow rate of $0.03 \mathrm{~L} / \mathrm{min}$. Figure 2 shows the configuration of the automated monitoring system, which includes on-line monitors and off-line laboratory analysis. Groundwater flows out from a depth of $\sim 100 \mathrm{~m}$, which was introduced into the gas-water separator for on-line monitors, while 


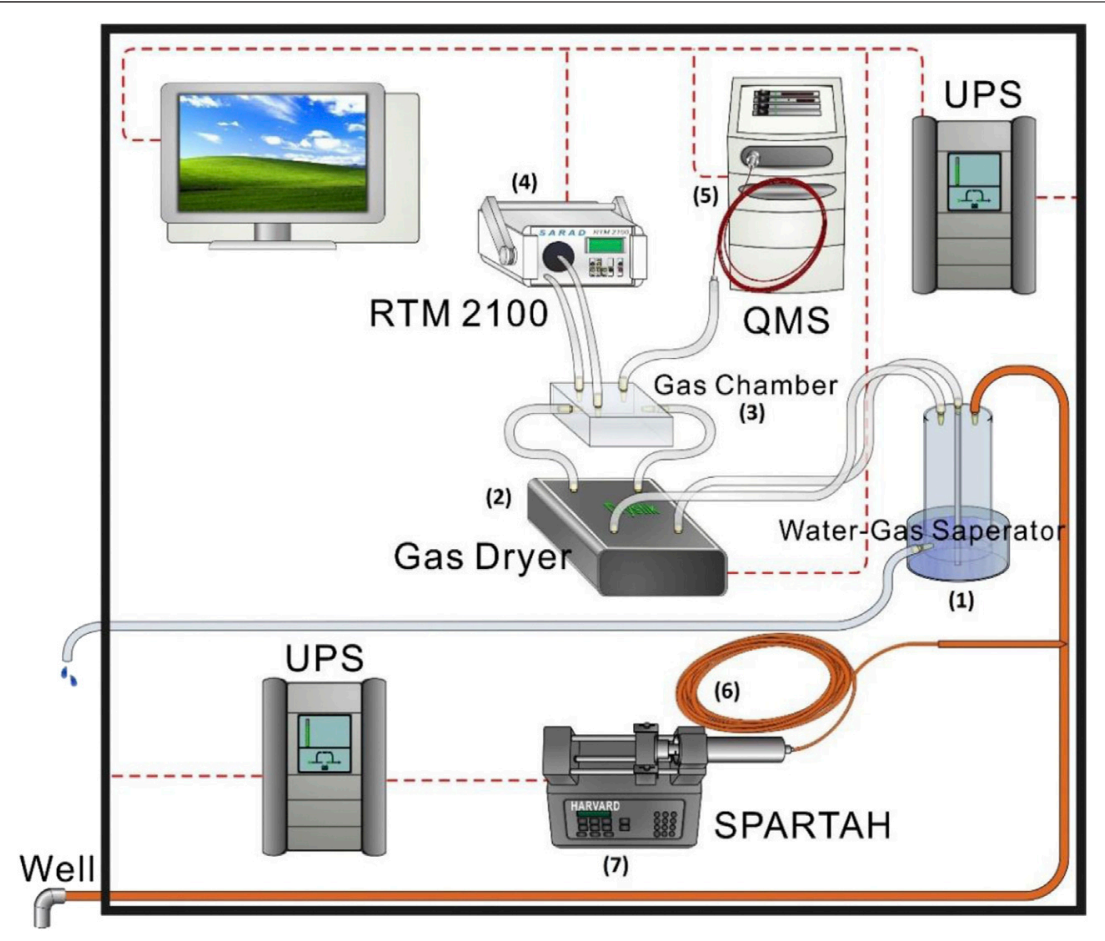

FIGURE 2 | A sketch of the monitoring station, including the dissolved gas analyzer, fluid collection system, and associated equipment.

groundwater was connected via the coils of $\mathrm{Cu}$ tubing to a storage device for off-line laboratory analysis. After passing through a condensing water trap and a DRYSTIK (Durridge Co.), the dry dissolved gases are split to (1) quadrupole mass spectrometer (QMS100, Stanford Research Systems, Inc.); and radon counter (RTM 2100, SARAD, Dresden, Germany) from a $\sim 1-\mathrm{L}$ chamber. The dissolved gas compositions were continuously analyzed through the QMS system at the interval of every $2 \mathrm{~min}$, while radon concentration was recorded once every $30 \mathrm{~min}$, then transmitted to the laboratory at the National Taiwan University via the Internet. The accuracy of Rn measurement is better than $\pm 10 \%$, and the analytical limit of detection is $\sim 30 \mathrm{~Bq} / \mathrm{m}^{3}$. The accuracy of QMS is approximately $1-10 \%$ according to different gas concentrations in the ranges of a percent (\%) to parts per million (ppm), and the analytical limit of detection is less than one ppm. Before gas monitoring at YS station, the QMS has been calibrated for the mass scale (to measure at the peak maximum) and quantified gas concentrations. A similar instrumental setup can be found in Yang et al. (2006).

The sampling and analysis procedure charts of the off-line laboratory are shown in Figure 3. The automatic sampling system for water samples is named the Syringe Pump Apparatus for the Retrieval and Temporal Analysis of Helium (SPARTAH) as a storage device for fluids designed by Barry et al. (2009). The system is composed of a syringe pump (model PHD 4400 by Harvard Apparatus) equipped with a $100 \mathrm{ml}$ stainless-steel syringe (the syringe volume can be upgraded) to provide a stable pumping force of up to $91 \mathrm{~kg}$ and accurate sampling volume calibration.

The coils of $\mathrm{Cu}$ tubing are composed of a length of $\sim 30.3 \mathrm{~m}$ and an inner diameter of $2.05 \mathrm{~mm}$ is used to connect with the syringe pump, which can be considered as the storage container. The coils of $\mathrm{Cu}$ tubing are filled with deionized (DI) water using the refill mode of the syringe pump before connection. The DI water is drawn into the stainless-steel syringe and is replaced by water from the wellhead during operation. The fluid is accurately and smoothly drawn into the syringe at a user-defined rate through the withdrawal mode operating by the syringe pump. To evaluate the feasibility of using the SPARTAH system in Taiwan, we first determine a constant flow rate of $0.0417 \mathrm{ml} / \mathrm{h}(1 \mathrm{ml} /$ day $)$ to collect groundwater for analyzing the ratio of hydrogen, oxygen, DIC, helium isotopes and the concentration of chloride during the period from January 20 to March 21, 2014 (the first period). The SPARTAH system was further performed for sampling groundwater at a constant flow rate of $0.2085 \mathrm{ml} / \mathrm{hr}(5 \mathrm{ml} /$ day $)$ for the second period, which mean the coils would have to be replaced approximately twenty days. That is, each batch of $\mathrm{Cu}$ coils can hold a total of $100 \mathrm{ml}$ of water samples, and the sample length of each copper tubing is about $30.3 \mathrm{~cm}$ for $1 \mathrm{ml}$ of water. Upon return to the laboratory, the batch of copper coils are immediately sectioned into one and five segments per day during the first period and the second period, respectively, using refrigeration clamps and labeled the date. The labeled $\mathrm{Cu}$ tubing then can be broken by a torsion to transferred water samples into the Teflon containers for further analysis. In this study, each section of $\mathrm{Cu}$ tubing contains $1 \mathrm{ml}$ of the water sample and which used to analyze the concentration of anion $\left(\mathrm{Cl}^{-}\right)$and dissolved inorganic carbon (DIC) in water and the ratio of DIC, hydrogen, oxygen, and helium isotopes. All measurements were analyzed within two weeks after sectioning the $\mathrm{Cu}$ tubing, except for helium analysis.

According to the capillary action, the sample in the Cu tubing is affected by 1) fluid diffusion and 2) fluid dispersion during 


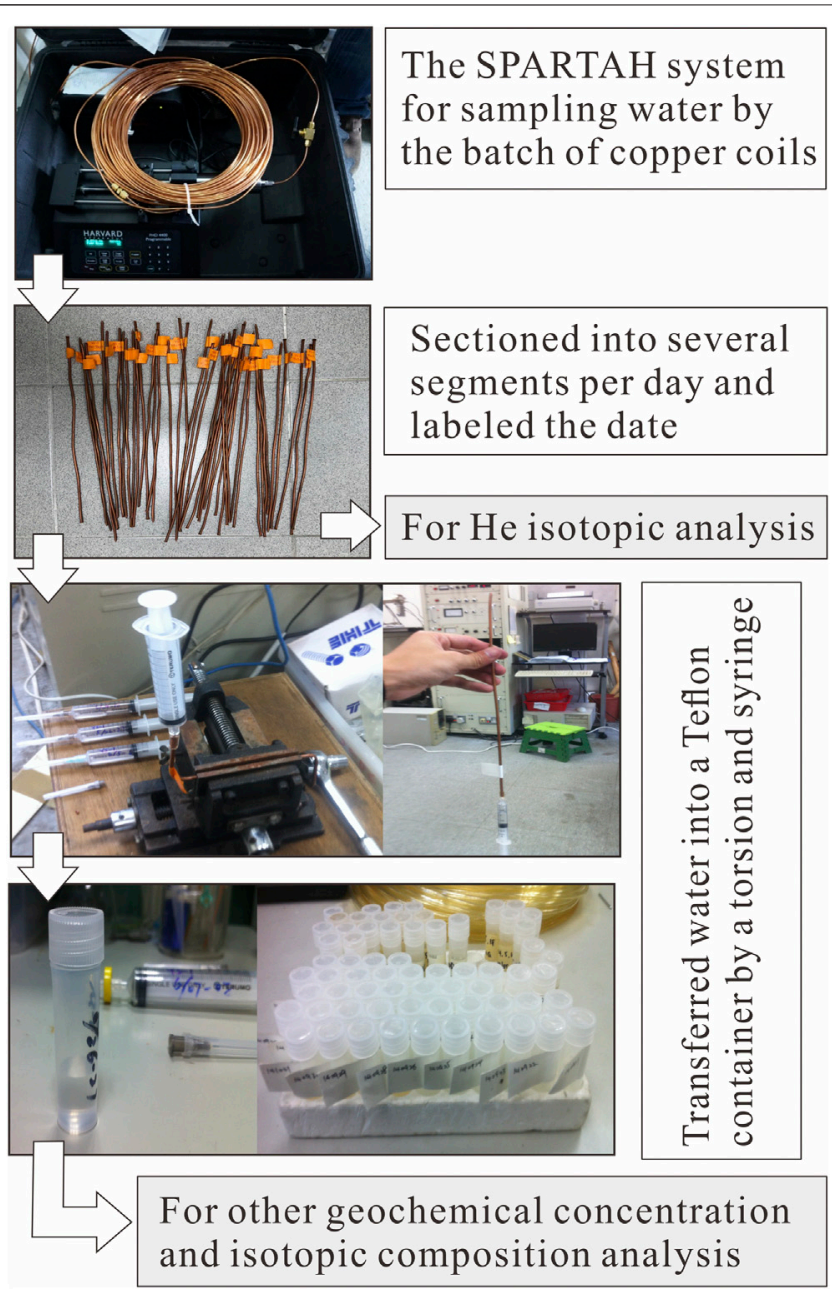

FIGURE 3 | The flowchart of the methodology illustrating the sampling and procedure used for analysis in water samples through the SPARTAH system.

sampling. According to the research experiment with the similar configuration conditions at a low flow rate (Tryon et al., 2001), it showed that after 6 months of copper tubing in storage, those two factors only made a slight impact on water samples. The trend of fluid chemical properties can yet be recognized in time series, even if it may be contaminated with a small perturbation (Barry et al., 2009).

The concentrations of chloride in the water samples were determined using an ion chromatography (Metrohm 882 Personal IC) at the Department of Geosciences, National Taiwan University, with a relative standard deviation of $<1.5 \%$ and a detection limit of $0.1 \mathrm{ppm}$ in weight.

Helium concentrations and isotopic ratios in water samples were directly analyzed from the $\mathrm{Cu}$ tubing sample after the Ultra-high Vacuum (UHV) extraction system and purification in the highvacuum inlet line of a MAP215E noble gas mass spectrometer at the Scripps Institution of Oceanography, University of California San Diego. The observed ${ }^{3} \mathrm{He} /{ }^{4} \mathrm{He}$ ratios were calibrated against atmospheric standard gas and were expressed relative to $\mathrm{Ra}$, where
$\mathrm{Ra}$ is the air ${ }^{3} \mathrm{He} /{ }^{4} \mathrm{He}$ ratio of $1.39 \times 10^{-6}$ (Poreda and Craig, 1989). This system can process $1 \mathrm{~cm}^{3}$ of water for helium isotope analysis at a precision $<2 \%$, and experimental details following a similar process were described in detail by Barry et al. (2009).

The concentration and stable carbon isotope composition of dissolved inorganic carbon (DIC) were conducted by an isotopic ratio mass spectrometer (Thermo-Finnigan MAT253, Bremen, Germany) at the Institute of Oceanography, National Taiwan University, equipped with a Kiel carbonate device (ThermoFinnigan) at which carbonate minerals react with phosphoric acids to at generating $\mathrm{CO}_{2}$ for downstream isotopic analysis. Observed carbon isotopic ratios were normalized to the Vienna Pee Dee Belemnite (V-PDB) and shown as $\delta$ values. The precision of carbon isotopic composition was $0.03 \%$ at $1 \sigma$.

Hydrogen and oxygen isotopes of water samples were analyzed using the Liquid-Water Isotope Analyzer (LWIA) by off-axis integrated-cavity laser spectroscopy (DLT-100, LGR Co. Ltd.) at the Department of Geosciences, National Taiwan University without any chemical preprocessing, following the procedure described in Lis et al. (2008) and Berman et al. (2009). Observed hydrogen and oxygen isotopic ratios were calibrated against five LGR standards (LGR 1A-5A) and converted into the conventional V-SMOW (Vienna Standard Mean Ocean Water) scale, presented as $\delta$ values. per mil (\%o). According to the manufacturer's specifications (Los Gatos Research Inc., 2008), the precision of $\delta^{18} \mathrm{O}$ and $\delta \mathrm{D}$ values were less than $0.6 \%$ and $0.2 \%$ at $1 \sigma$, respectively. The $\delta$ notation is defined as:

$$
\delta(0 / 00)=\left[\left(\mathrm{R}_{\text {sample }} / \mathrm{R}_{\text {standard }}\right)-1\right] \times 1000
$$

where $\mathrm{R}$ is the ratio of ${ }^{13} \mathrm{C} /{ }^{12} \mathrm{C},{ }^{2} \mathrm{H} /{ }^{1} \mathrm{H}$, or ${ }^{18} \mathrm{O} /{ }^{16} \mathrm{O}$.

Hourly precipitation is available from a meteorological station of the Central Weather Bureau (CWB) of Taiwan, located at about $3 \mathrm{~km}$ from the YS station. Seismic data used in this study are taken from the earthquake catalogs of CWB of Taiwan. The distribution of each earthquake's intensity to present the amount of shaking could also be detected, meanwhile, the local intensity of an earthquake to the YS site then could be known. There were 495 earthquakes with local magnitudes (ML) ranging from 2.0 to 5.9 in the Taiwan area during the deployment period. Only when those earthquakes with local intensity $\geq$ two around YS station together with, the distance between station and earthquake of the epicenter is $\leq 30 \mathrm{~km}$ for $\mathrm{M} \geq 4$ or the distance is $30-110 \mathrm{~km}$ for $\mathrm{M}$ $\geq 5$ (Table 1), which are considered significant to the monitoring site (e.g., Yang et al., 2005; Fu et al., 2017).

\section{RESULTS AND DISCUSSIONS}

\section{Temporal Variation of Geochemical Compositions During the First Deployment}

Fourteen helium isotope and concentration results, along with the ratio of hydrogen, oxygen, carbon isotopes, and chloride concentration from the $\mathrm{Cu}$ coils during the first deployment from January 20 to March 21, 2014, are presented in Table 2 and Figure 4. The range in ${ }^{3} \mathrm{He} /{ }^{4} \mathrm{He}$ and $\delta^{13} \mathrm{C}$ values of dissolved inorganic carbon (DIC) are observed from 0.42 to $0.56 \mathrm{Ra}(1 \mathrm{Ra}=$ 
TABLE 1 | Catalog of related earthquakes ${ }^{a}$ occurring in Taiwan from January 20 to March 21, 2014, and May 1 to November 30,2014

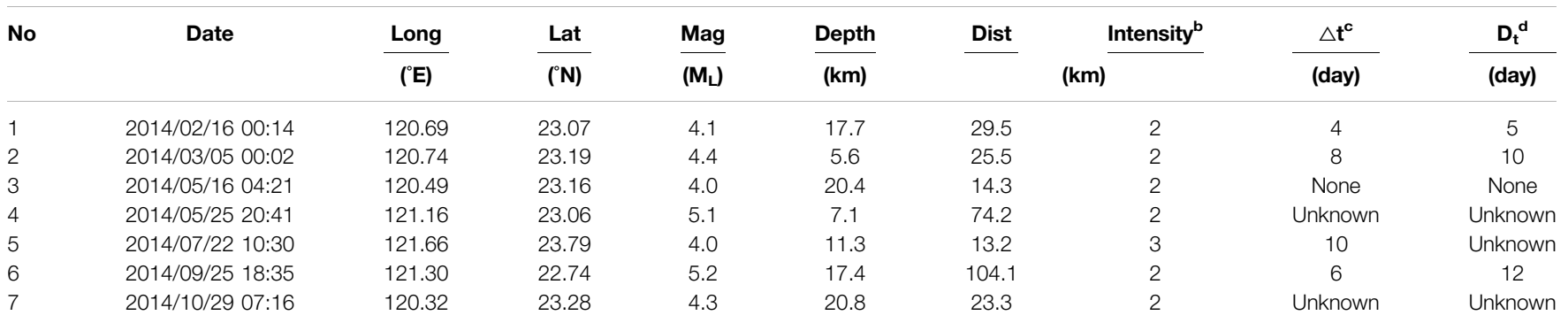

${ }^{a}$ There were in total 495 earthquakes recorded in Taiwan during this period (Figure 1). Only those earthquakes with local intensity $\geq 2$ and the epicenter distance $\leq 30 \mathrm{~km}$ with $\mathrm{M} \geq 4$, or the epicenter distance $\leq 110 \mathrm{~km}$ with $M \geq 5$, are considered significant to the monitoring site.

bIntensity of each earthquake is presented the amount of shaking around the monitoring station.

${ }^{c}$ Time difference between the anomalous peak of geochemical compositions and the earthquake event.

${ }^{d}$ Duration of the anomaly.

atmospheric ${ }^{3} \mathrm{He} /{ }^{4} \mathrm{He}$ value) and -20.01 to $-0.07 \%$, respectively, similar to the previous values of $<0.4 \mathrm{Ra}$ for the study area. The $\mathrm{He} / \mathrm{Ne}$ value (as X has shown in Table 1) varies from 7.69 to 512 and ${ }^{4} \mathrm{He}$ concentration from 24.1 to $1060 \mathrm{cc} \mathrm{STP} / \mathrm{gH}_{2} \mathrm{O}$. The $\delta \mathrm{D}$ and $\delta^{18} \mathrm{O}$ values range from -11.37 to $-5.00 \%$ and -1.30 to $-0.07 \%$, respectively, and the concentration of chloride range from 12,700 to $13,500 \mathrm{ppm}$. Temporal variations of all measurements were relatively small. Moreover, we can confirm that the DI water in the coils of $\mathrm{Cu}$ tubing was replaced by groundwater from the well based on a low value of ${ }^{3} \mathrm{He} /{ }^{4} \mathrm{He}$ ratio and a very high chloride concentration. Taking together all observations is shown that the SPARTAH system successfully retrieved fluid samples during the first deployment.

The background values were determined using the mean value plus two standard deviations shown by the yellow bar to recognize their background and anomalous value (Figure 4). Some substantial but short increase in the ${ }^{3} \mathrm{He} /{ }^{4} \mathrm{He}, \delta^{13} \mathrm{C}_{\text {DIC }}$, and ${ }^{4} \mathrm{He}$ data can be observed during this deployment period. Changes in those geochemical parameters from February 12 to
16,2014 , may be associated with a local earthquake $(\mathrm{M}=4.1)$, which occurred on February 16, 2014, approximately $29.5 \mathrm{~km}$ to YS station. Similar anomalies were observed from February 25 to March 7, 2014, followed by an earthquake, which occurred on March 5, 2014, with a focal depth of $5.6 \mathrm{~km}$, approximately $25.5 \mathrm{~km}$ to YS station with magnitude 4.4 . As in the case of the first deployment, not only ${ }^{4} \mathrm{He}$ concentrations but also the isotopic value of ${ }^{3} \mathrm{He} /{ }^{4} \mathrm{He}$ and $\delta^{13} \mathrm{C}_{\text {DIC }}$ presented the valuable indicators for tracing the possible earthquake precursor. However, $\mathrm{Cl}^{-}$concentrations, $\delta \mathrm{D}$, and $\delta^{18} \mathrm{O}$ values did not change significantly during this period.

\section{Temporal Variation of Geochemical Compositions During the Second Deployment}

Continuous on-line monitoring and off-line laboratory analysis at the YS station started from May 1 to November 30, 2014, for the second period. The concentration and ratio of dissolved gases,

TABLE 2 | Helium isotope and relative abundance characteristics from January 20 to March 21, 2014.

\begin{tabular}{|c|c|c|c|c|c|c|}
\hline Sample ID & $\mathbf{R}_{\mathrm{m}} / \mathbf{R}_{\mathrm{a}}{ }^{\mathrm{a}}$ & $\mathbf{X}^{\mathbf{b}}$ & $\mathbf{R}_{\mathrm{c}} / \mathbf{R}_{\mathrm{a}}{ }^{\mathrm{c}}$ & $\begin{array}{c}{\left[{ }^{4} \mathrm{He}_{\mathrm{m}}{ }^{\mathrm{d}} \mathrm{cc}\right.} \\
\text { STP } / \mathrm{g} \mathrm{H}_{2} \mathrm{O}\left(\times 10^{-9}\right)\end{array}$ & $\begin{array}{c}{\left[{ }^{4} \mathrm{He}_{c}{ }^{d} \mathrm{cc}\right.} \\
\text { STP/g H} / \mathrm{g}_{2} \mathrm{O}\left(\times 10^{-9}\right)\end{array}$ & $\delta^{13} C_{D I C}(\%)$ \\
\hline $2014 / 01 / 27$ & 0.54 & 7.69 & $0.47 \pm 0.01$ & 67.5 & 58.8 & -16.91 \\
\hline 2014/02/09 & 0.49 & 11.9 & $0.44 \pm 0.01$ & 62.9 & 57.6 & -14.31 \\
\hline $2014 / 02 / 12$ & 0.50 & 14.1 & $0.46 \pm 0.01$ & 195 & 181 & -2.07 \\
\hline $2014 / 02 / 13$ & 0.55 & 13.4 & $0.52 \pm 0.01$ & 169 & 156 & -15.84 \\
\hline $2014 / 02 / 14$ & 0.50 & 10.1 & $0.45 \pm 0.01$ & 50.9 & 45.9 & -5.84 \\
\hline $2014 / 02 / 16$ & 0.53 & 11.4 & $0.48 \pm 0.02$ & 47.8 & 43.6 & -0.07 \\
\hline $2014 / 02 / 21$ & 0.44 & 15.2 & $0.42 \pm 0.01$ & 60.5 & 55.7 & -17.37 \\
\hline $2014 / 02 / 25$ & 0.56 & 8.90 & $0.51 \pm 0.02$ & 41.1 & 36.5 & -8.82 \\
\hline $2014 / 02 / 27$ & 0.49 & 10.7 & $0.44 \pm 0.01$ & 47.1 & 42.7 & -17.89 \\
\hline 2014/03/01 & 0.48 & 29.4 & $0.46 \pm 0.01$ & 519 & 501 & -3.34 \\
\hline 2014/03/05 & 0.43 & 512 & $0.43 \pm 0.01$ & 1300 & 1300 & -20.01 \\
\hline $2014 / 03 / 07$ & 0.41 & 165 & $0.44 \pm 0.01$ & 2,230 & 2220 & -18.38 \\
\hline 2014/03/09 & 0.44 & 33.3 & $0.43 \pm 0.01$ & 99.7 & 96.7 & ND \\
\hline $2014 / 03 / 15$ & 0.60 & 11.4 & $0.56 \pm 0.03$ & 55.6 & 50.8 & -12.77 \\
\hline
\end{tabular}

All reported errors are at the $1 \sigma$ level.

${ }^{a} R_{m} / R_{a}$ is measured ${ }^{3} \mathrm{He} /{ }^{4} \mathrm{He}$ ratio divided by the ${ }^{3} \mathrm{He} /{ }^{4} \mathrm{He}$ in air $=1.4 \times 10^{-6}$.

${ }^{b} \mathrm{X}=\left({ }^{4} \mathrm{He} /{ }^{20} \mathrm{Ne}\right)_{\text {measured }}\left({ }^{4} \mathrm{He} /{ }^{20} \mathrm{Ne}\right)_{\text {air }} \times \beta_{\mathrm{Ne}} / \beta_{\mathrm{He}}$ and $\beta$ represents the Bunsen coefficient from (Weiss, 1971) assuming a groundwater recharge temperature of $15^{\circ} \mathrm{C}$.

${ }^{c} R_{d} / R_{a}$ is the air-corrected He isotope ratio $=\left[\left(R_{m} / R_{a} \times X\right)-1\right] /(X-1)$.

${ }^{d}$ Dissolved He concentrations are air-corrected where $[\mathrm{He}]_{C}=\left([\mathrm{He}]_{m} \times(X-1)\right) / X$. 


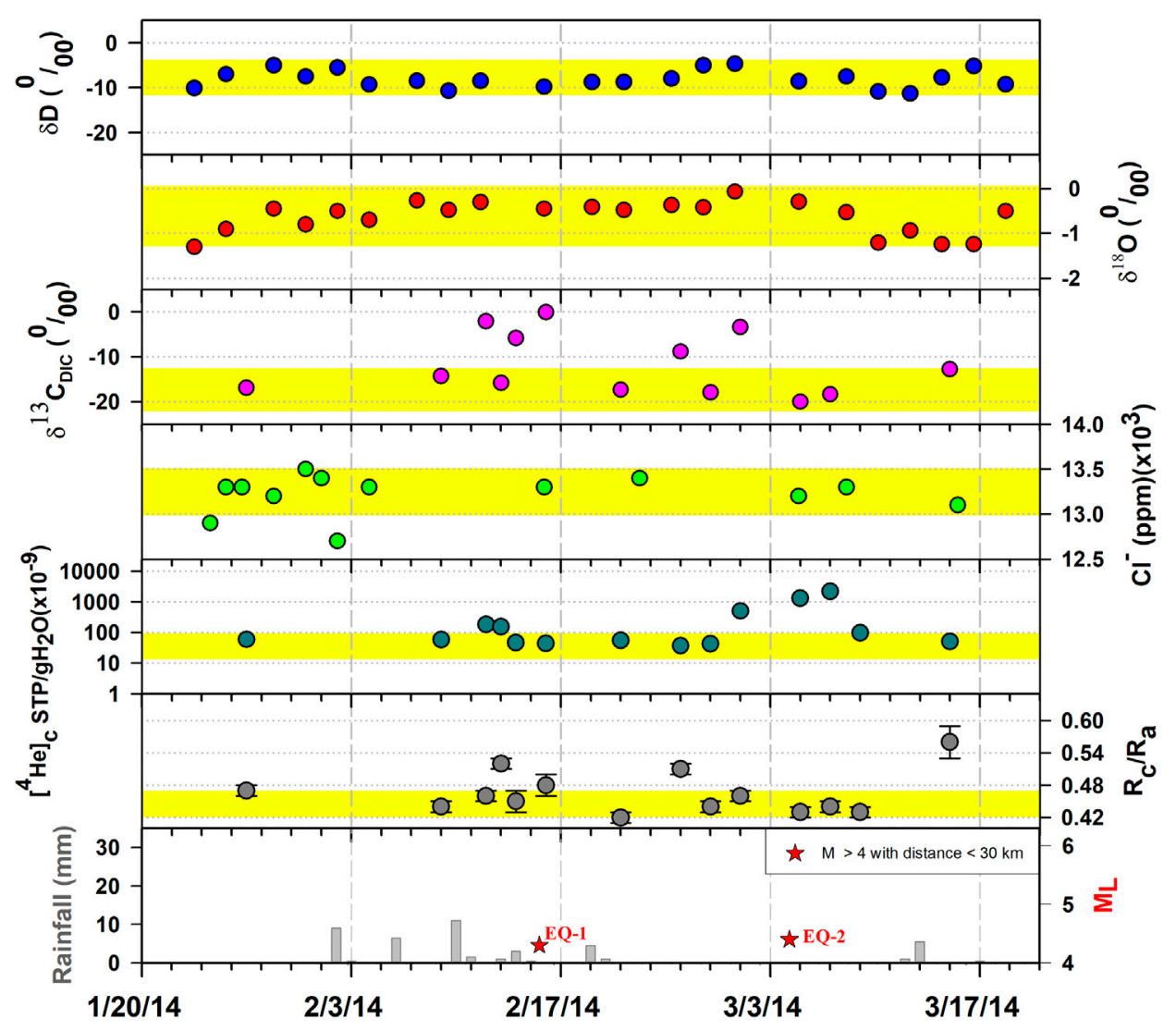

FIGURE 4 | The temporal variations of $\delta \mathrm{D}, \delta^{18} \mathrm{O}, \delta^{13} \mathrm{C}_{\mathrm{DIC}}$, and ${ }^{3} \mathrm{He} /{ }^{4} \mathrm{He}$ values as well as ${ }^{4} \mathrm{He}$ and chloride concentrations from January 20 to March $21,2014$. Horizontal yellow bar indicates two standard deviations from the mean of the observed results. Red dashed line denotes the date of the specific seismic events. The magnitude of related earthquakes with local intensity $\geq 2$ and hourly rainfall data are also included. Red star symbols indicate that the epicenter distance of the earthquake to the station was $\leq 30 \mathrm{~km}$ with a magnitude $\geq 4$.

as well as the isotopic ratio of hydrogen, oxygen, DIC, and the concentration of DIC and chloride, were recorded (Figure 5). The hourly average of dissolved gases had chemical compositions of $90.2-96.5 \%$ for $\mathrm{CH}_{4}, 0.8-2.0 \%$ for $\mathrm{O}_{2}, 1.7-6.7 \%$ for $\mathrm{N}_{2}$, $0.13-0.25 \%$ for $\mathrm{CO}_{2}, 0.04-0.11 \%$ for $\mathrm{Ar}$, and $748-1391 \mathrm{~Bq} / \mathrm{m}^{3}$ for $\mathrm{Rn}$. The ratio of $\mathrm{CH}_{4} / \mathrm{N}_{2}, \mathrm{~N}_{2} / \mathrm{CO}_{2}$, and $\mathrm{CH}_{4} / \mathrm{CO}_{2}$ range from 13.5 to $56.9,9.9$ to 41.5 , and 375.2 to 689.0 . The range in $\delta \mathrm{D}, \delta^{18} \mathrm{O}$, and $\delta^{13} \mathrm{C}_{\mathrm{DIC}}$ values were presented from -11.12 to $-4.21 \%$, -0.90 to $0.52 \%$, and -19.32 to $-8.63 \%$, respectively. The concentration of $30.5-38.4 \mathrm{mM}$ for DIC and 12,900 to $14,700 \mathrm{ppm}$ for chloride were observed. Two significant but short changes in several observed results can be observed during the second deployment. However, some discrete changes and a loss of the time-series in the monitoring data occasionally are due to manual factor calibration, system servicing, and supply problems. It is noted that there is a lack of helium results during the second deployment because of some technical problems for the arrangement of $\mathrm{Cu}$ tubing samples to the Scripps Institution of Oceanography.

Continuous dissolved gas concentrations in $\mathrm{CH}_{4}, \mathrm{CO}_{2}$, and $\mathrm{Ar}$ together with the ration of $\mathrm{CH}_{4} / \mathrm{N}_{2}$ showed the substantial increase after July 12 until July 21, 2014, with the highest value, while the decrease in dissolved gas concentrations of $\mathrm{O}_{2}$ and $\mathrm{N}_{2}$ were observed simultaneously (Figures 5A,B). It suggests an evidence that the change was not induced by air contamination. There is a noticeable decrease in gas compositions, followed by a local earthquake with magnitude 4 , which occurs on July 22, 2014. The earthquake with a focal depth of $11.3 \mathrm{~km}$ is only located at about $13.2 \mathrm{~km}$ away from the station. The timing is consistent with the period of the observed $\delta^{18} \mathrm{O}$ anomalies on July 18,2014 , the $\delta^{13} \mathrm{C}_{\text {DIC }}$ changes on July 17 , 2014, and higher fluctuation in $\mathrm{Cl}^{-}$concentrations on July 14 and 18, 2014 (Figure 5C).

An abrupt change in dissolved gas concentrations in $\mathrm{CH}_{4}$ and $\mathrm{CH}_{4} / \mathrm{N}_{2}$, as well as a slight increase in $\mathrm{Rn}$ concentrations were observed from September 19 to October 1, 2014, and September 24 to October 7, 2014, respectively; meanwhile, the significantly decreasing trend in $\mathrm{O}_{2}, \mathrm{~N}_{2}, \mathrm{Ar}$, and $\mathrm{N}_{2} / \mathrm{CO}_{2}$ were found (Figures 5A,B). During the observed gas anomalies, there is an earthquake $(M=5.2)$ occurring on September 25, 2014, with a focal depth of $17.4 \mathrm{~km}$ and an epicenter distance of $104.1 \mathrm{~km}$ from the station. Similarly, the timing is consistent with the period of the observed $\delta^{13} \mathrm{C}_{\mathrm{DIC}}$ changes of -9.96 to $-8.63 \%$ on September 22, 23, and 25, 2014, and higher variations in $\mathrm{Cl}^{-}$ concentrations of 1.42-1.47 ppm on September 21 and 28, 2014 (Figure 5C). 

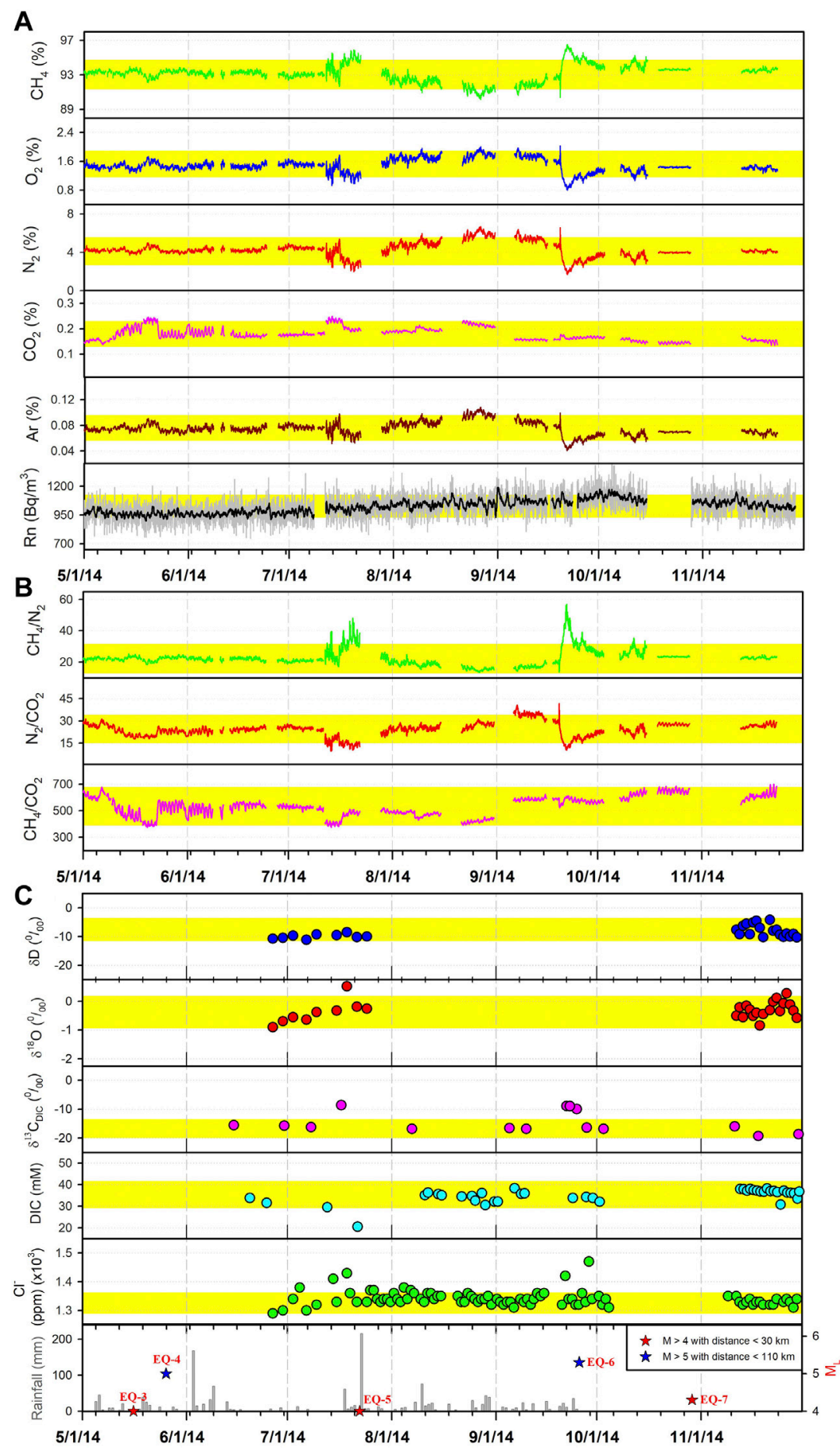

FIGURE 5 | The temporal variations of (A) concentration and (B) ratio of dissolved gases as well as $(\mathbf{C})$ water chemical compositions $\left(\delta \mathrm{D}, \delta^{18} \mathrm{O}\right.$, and $\delta^{13} \mathrm{C}_{\mathrm{DIC}}$ values along with DIC and chloride concentrations) from May 1 to November 30, 2014. Horizontal yellow bar indicates two standard deviations from the mean of the observed results. The magnitude of related earthquakes with local intensity $\geq 2$ and hourly rainfall data are also included. The star symbols in different colors indicate that the epicenter distance of the earthquake to the station was $\leq 30 \mathrm{~km}$ (red) with a magnitude $\geq 4$ and $\leq 110 \mathrm{~km}$ (blue) with a magnitude $\geq 5$, respectively.

It is noted that a slight fluctuation of gas compositions can be observed from May 17 to 23, 2014, two days prior to the EQ-4 $(M=5.2)$, which occurs on May 25, 2014, approximately $74.2 \mathrm{~km}$ to the station. Furthermore, the hypocenter depth of EQ-4 is only $7.1 \mathrm{~km}$, which may affect pre-stress transfer across due to the complex tectonic structures in the shallow crust. It may be 
explained that no substantial anomaly was obviously found before the EQ-4. However, there is no anomaly related to the EQ-3 and EQ-7, which occurred on May 16 and October 29, 2014, with a hypocenter depth greater than $20 \mathrm{~km}$. During the second deployment, all observations have demonstrated that the automatic system of online monitoring and the SPARTA for offline analysis is feasible for long-term continuous seismogeochemical research in this area.

\section{The Possible Effect on the SPARTAH System}

Tryon et al. (2001) have shown a tracer record from fluid samples through approximately $75 \mathrm{~m}$ of $\mathrm{Cu}$ tubing for more than two months and pointed out that the diffusion and dispersion of the tracer are slight during more than two months sampling period. Déhais et al. (2016) have reported that the diffusion of helium in the $\mathrm{Cu}$ tube through the SPARTAH system was slight during four to six months and recommended a shorter sampling duration of two months to be appropriately deployed on the field for obtaining the reliable preservation of the information. This study operated the SPARTAH system to obtain groundwater samples and replace the Cu coils approximately every two months and twenty days for the first and second deployment, respectively. All groundwater samples analysis was completed within two weeks after taking the $\mathrm{Cu}$ coils back from the station, except for helium analysis. The duration of fluid in the $\mathrm{Cu}$ coil in the study is similar to the previous studies mentioned above. Several substantial geochemical compositions were found for a short period to provide excellent proofs without any significant contamination by diffusion or dispersion process. Therefore, the effect of diffusion and dispersion on the SPARTAH system can be ignored.

\section{Mechanism for Geochemical Changes}

The mechanism for changes in the chemical compositions of subsurface water bodies can be attributed to several processes: 1) water-rock interactions; 2) the mixing of groundwater and formation or pore waters; 3) by the mixing of different reservoirs with different chemical compositions; 4) by the mixing of meteoric waters; 5) artificial pollutants (Igarashi et al., 1995; Song et al., 2006; Reddy et al., 2011; Skelton et al., 2014; Sano et al., 2020). The processes (1) and (2) may gradually cause the hydro-chemical changes during a long period of time, resulting in a shift from an equilibrium between water and rock because of increased exposure of reactive surfaces to the fluid. According to the observed temporal variations of all geochemical anomalies only occurring a few days before the relevant earthquake in a short duration, the processes (1) and (2) then can be ruled out.

Groundwater is mainly derived from meteoric water, including precipitation, and river and lake water (Mizota and Kusakabe, 1994). The origin and evolution of the groundwater can be evaluated by the hydrogen and oxygen isotopes (Claesson et al., 2004; Peng et al., 2010). Their signatures can characterize the groundwater samples in Craig's diagram (Craig, 1961), and their relationship between the $\delta \mathrm{D}$ and $\delta^{18} \mathrm{O}$ values of

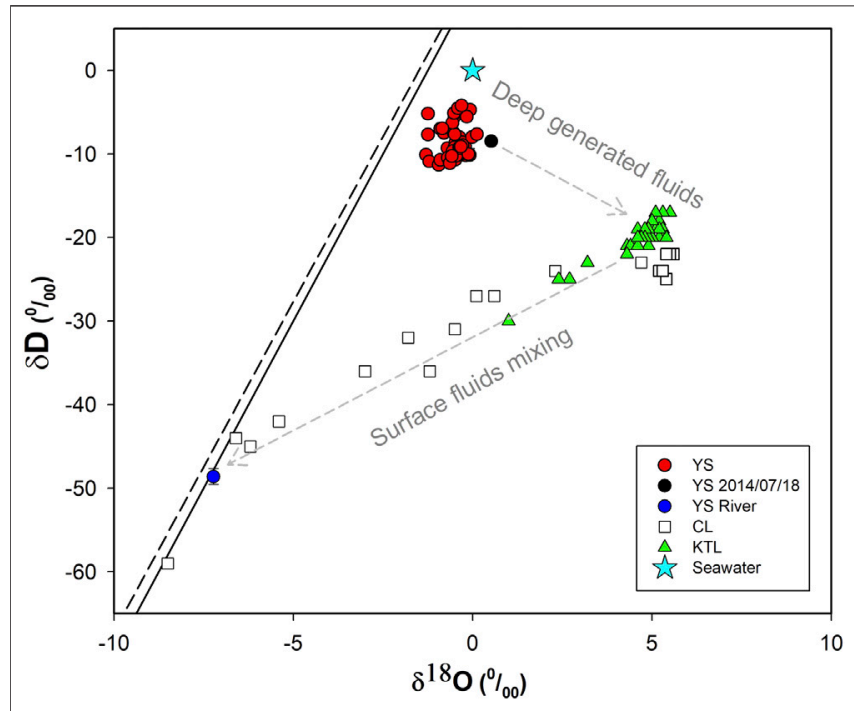

FIGURE 6 | Plot of $\delta D$ and $\delta^{18} \mathrm{O}$ for groundwater samples in this study with literature results of $\mathrm{CL}$ and KTL for comparison (Chan, 2001). Seawater composition, local meteoric water line (Wang et al., 2001; solid line), and global meteoric water line (Craig, 1961; dash line) are shown for reference.

groundwater samples from the YS well is presented in Figure 6. Those fluids have slightly higher $\delta^{18} \mathrm{O}$ values and have lower $\delta \mathrm{D}$ values than seawater, suggesting those were not significantly contributed by surface water. The nearly constant $\delta \mathrm{D}$ and $\delta^{18} \mathrm{O}$ composition of YS over time, possibly reflecting the compositions of formation water. Meanwhile, the large $\delta \mathrm{D}$ and $\delta^{18} \mathrm{O}$ variations at CL and KTL over time indicated the potential of two end members mixing between formation water and meteoric water (Chan, 2001). The higher oxygen isotopic value of YS was detected on July 18, 2014, four days before the EQ-5, which occurs on July 22, 2014. We proposed that a slight contribution of higher $\delta^{18} \mathrm{O}$ was attributed to the mixing of different groundwater types, which may be associated with the deep generated fluids of CL and KTL.

The higher ${ }^{3} \mathrm{He} /{ }^{4} \mathrm{He}$ value with enrichment of $\mathrm{CO}_{2}$ and the lower ${ }^{3} \mathrm{He} /{ }^{4} \mathrm{He}$ value with enrichment of $\mathrm{CH}_{4}$ would represent the magmatic and crustal end-member, respectively, as suggested by the data from CL and KTL (Yang et al., 2004; Yang, 2008), which may provide two different potential sources around the studied area for the gas and fluid interacting with the YS well. Since the samples during the first deployment exhibit the lower ${ }^{3} \mathrm{He} /{ }^{4} \mathrm{He}$ ratios as well as a ${ }^{4} \mathrm{He} /{ }^{20} \mathrm{Ne}$ variation of $8.9-512$, far exceeding the ratio of air (0.318) (Sano and Wakita, 1985), air contamination cannot be the primary process responsible for the observed differences in the ${ }^{3} \mathrm{He} /{ }^{4} \mathrm{He}$ values. As no obvious mantle signal and higher $\mathrm{CO}_{2}$ concentrations were found in the monitoring results of YS, a contribution of mantle helium associated with higher $\mathrm{CO}_{2}$ from CL can be excluded. Moreover, Yang et al. (2003) reported that the average $\mathrm{Rn}$ concentrations of approximately $16,800 \mathrm{~Bq} / \mathrm{m}^{3}$ at the $\mathrm{CL}$ site and proposed $\mathrm{Rn}$ exhalation is mainly controlled by the $\mathrm{CO}_{2}$ carrier gases along the CKF. Similarly, Etiope and Martinelli (2002) suggested that 
carrier gases (e.g., $\mathrm{CH}_{4}$ and $\mathrm{CO}_{2}$ ) may play an essential role in controlling the migration and transportation of $\mathrm{Rn}$ in the fractured zone toward the surface. Therefore, very slight increases in $\mathrm{Rn}$ and $\mathrm{CO}_{2}$ prior to an impending earthquake suggest that CL may not be the primary contributor to change gas compositions at the YS site. KTL could be the potential source to provide a higher $\delta^{18} \mathrm{O}$ fluid but not $\mathrm{CL}$, due to a lower ${ }^{3} \mathrm{He} /{ }^{4} \mathrm{He}$ value at $\mathrm{YS}$ without any significant mantle signature. Furthermore, an additional $\mathrm{CH}_{4}$ inputting was observed from July 12 to July 21, 2014, that may indicate a potential contribution with enrichment of $\mathrm{CH}_{4}$ around the YS site. It is another evidence to support that KTL can be the candidate for providing a fluid source. Hence, based on those evidences, we deduced that the mechanism for pre-geochemical anomalies was caused by rapid fluids mixing between YS and KTL area as the process (3).

No correlated relationships between the anomalies of $\mathrm{Cl}^{-}$in the temporal variations and hourly precipitation were found during the monitoring period (Figure 5), highly suggesting that the observed temporal variations in the geochemical compositions were not induced by the meteoric water flowing down into the circulation system of the subsurface water system. For a similar reason, artificial pollutants cannot cause hydrogeochemical changes in this study. Therefore, the processes (4) and (5) can be ignored.

We observed continuous dissolved gases together with chemical and isotopic changes in groundwater sampled at YS well near the active CKF, those of anomalies before some specific earthquakes with $M \geq 4$ and $\leq 30 \mathrm{~km}$ and $M \geq 5$ and $\leq 110 \mathrm{~km}$ away from the station. Those events have induced the local intensity $\geq 2$ around the monitoring region. According to those findings and interpretations mentioned above, we proposed preseismically induced gas-fluid source mixing, with the connection of different fluids due to the development of microcracks causing changes in rock permeability of the formation below the YS station. The observed compositions returned to background levels within a few days after the duration of the anomaly due to the closing of microfractures reducing the permeability of the rock.

\section{CONCLUSION}

In the present study, we applied on-line monitoring for continuous dissolved gas compositions and off-line analysis by the SPARTAH system for automated sampling groundwater samples at YS station, located around the active fault zone in southwestern Taiwan. The major findings of this study are listed below:

(1) The significant changes of dissolved gases (e.g., $\mathrm{CH}_{4}, \mathrm{CO}_{2}$, $\mathrm{Ar}$, and $\mathrm{CH}_{4} / \mathrm{N}_{2}$ ) together with anomalous hydrogeochemical compositions (e.g., $\delta^{18} \mathrm{O}, \delta^{13} \mathrm{C}_{\mathrm{DIC}}$, DIC, and $\mathrm{Cl}^{-}$concentration) may be considered good indicators with high confidence related to the specific earthquake event in this area. Meanwhile, oxygen and nitrogen are relevant indexes for evaluating air-contamination of the observed results.
(2) Our observations demonstrate that this automatic monitoring and sampling system operating at the active fault zone is feasible for long-term continuous seismogeochemical research in this area. Taking the variations of multi-anomalies can be recognized from a few to several days before an earthquake with local intensity $\geq$ two, that could be used to have a reliable information about the short-term precursor.

(3) We propose a potential mechanism for geochemical changes, suggesting that those anomalies can be attributed to mixing different fluids (e.g., KTL) from different geochemical signatures caused by strain-induced changes in the permeability of surrounding formation around the YS station.

(4) The SPARTAH system could be a useful technique for collecting any fluids of interest that support within the specified time interval sampling depend on the syringe volume. Therefore, we consider that it could be applied not only to earthquake precursors but also other research purposes, for example, chemical weathering and water pollution.

\section{DATA AVAILABILITY STATEMENT}

The raw data supporting the conclusions of this article will be made available by the authors, without undue reservation, to any qualified researcher.

\section{AUTHOR CONTRIBUTIONS}

CCF was responsible for the design and organization of the work and writing the manuscript. CWL was responsible for the collection of data and analysis of samples. TFY and DRH provided the writing ideas of the paper. $\mathrm{CHC}, \mathrm{VW}, \mathrm{AK}$ and LCL were involved in the data interpretation.

\section{FUNDING}

The research is supported by grants MOST 108-2116-M-002-025, MOST 108-2116-M-001-024, and MOST 109-2628-M-001-002MY3 through the Ministry of Science and Technology (MOST).

\section{ACKNOWLEDGMENTS}

We deeply dedicate this paper to the late Prof. Tsanyao Frank Yang (TFY), who passed away on March 12, 2015 at the age of 54 and the late Prof. David Raymond Hilton (DRH), who passed away on January 7, 2018 at the ages of 59. Prof. Yang had worked as a geochemist at the Department of Geosciences, National Taiwan University (NTU), Taiwan, for more than 20 years and Prof. Hilton was a geochemist at Scripps Institution of Oceanography at the University of California San Diego 
(UCSD), for more than 30 years. Their passions for research included setting new standards for relevant measurements, which enables us to present our work here. We thank Mr. K.W. Wu and

\section{REFERENCES}

Barry, P. H., Hilton, D. R., Tryon, M. D., Brown, K. M., and Kulongoski, J. T. (2009). A new syringe pump apparatus for the retrieval and temporal analysis of helium in groundwaters and geothermal fluids. Geochem. Geophys. Geosyst. 10 (5), Q05004. doi:10.1029/2009GC002422

Berman, E. S., Gupta, F. M., Gabrielli, C., Garland, T., and McDonnell, J. J. (2009). High-frequency field-deployable isotope analyzer for hydrological applications. Water Resour. Res. 45 (10), W10201. doi:10.1029/2009WR008265

Chan, P. S. (2001). $\delta^{18} \mathrm{O}$ and $\delta \mathrm{D}$ of spring waters from active structure zones, southern Taiwan. MS thesis. Taipei: Dep. Geosci. Nat. Taiwan Univ., 80 [in Chinese with English abstract].

Chao, H. C., You, C. F., and Sun, C. H. (2010). Gases in Taiwan mud volcanoes: chemical composition, methane carbon isotopes, and gas fluxes. Appl. Geochem. 25 (3), 428-436. doi:10.1016/j.apgeochem.2009.12.009

Chao, H. C., You, C. F., Wang, B. S., Chung, C. H., and Huang, K. F. (2011). Boron isotopic composition of mud volcano fluids: implications for fluid migration in shallow subduction zones. Earth Planet. Sci. Lett. 305 (1, 2), 32-44. doi:10.1016/ j.epsl.2011.02.033

Chao, H. C., You, C. F., Liu, H. C., and Chung, C. H. (2013). The origin and migration of mud volcano fluids in Taiwan: evidence from hydrogen, oxygen, and strontium isotopic compositions. Geochim. Cosmochim. Acta 114, 29-51. doi:10.1016/j.gca.2013.03.035

Chen, C. H., Wang, C. H., Wen, S., Yeh, T. K., Lin, C. H., Liu, J. Y., et al. (2013). Anomalous frequency characteristics of groundwater level before major earthquakes in Taiwan. Hydrol. Earth Syst. Sci. 17 (5), 1693-1703. doi:10. 5194/hess-17-1693-2013

Chia, Y., Wang, Y. S., Chiu, J. J., and Lin, C. W. (2001). Changes of groundwater level due to the 1999 Chi-Chi earthquake in the Choshui River alluvial fan in Taiwan. Bull. Seismol. Soc. Am. 91 (5), 1062-1068. doi:10.1785/0120000726

Claesson, L., Skelton, A., Graham, C., Dietl, C., Morth, M., Torssander, P., et al. (2004). Hydrogeochemical changes before and after major Earthquake. Geology 32 (8), 641-644. doi:10.1130/g20542.1

Craig, H. (1961). Isotopic variations in meteoric waters. Science 133 (3465), 1702-1703. doi:10.1126/science.133.3465.1702

Déhais, T., Burnard, P., Pik, R., Caracausi, A., and Zimmermann, L. (2016). "Experimental determination of helium diffusion in automated sampling apparatus (SPARTAH): implications for preservation of individual peaks signal," in Poster session presented at developments in noble gas understanding and expertise, Vandoeuvre-lès-Nancy, France, April 13-15, 2016. Available at: http://helium.crpg.cnrs-nancy.fr/DINGUE-4/home.html.

Etiope, G., and Martinelli, G. (2002). Migration of carrier and trace gases in the geosphere: an overview. Phys. Earth Planet. Inter. 129 (3, 4), 185-204. doi:10. 1016/s0031-9201(01)00292-8

$\mathrm{Fu}, \mathrm{C}$. C., and Lee, L. C. (2018). "Continuous monitoring of fluid and gas geochemistry for seismic study in Taiwan," in Pre-earthquake processes: a multidisciplinary approach to earthquake prediction studies. Editors D. Ouzounov, S. Pulinets, K. Hattori, and P. Taylor (Hoboken, NJ: John Wiley and Sons, Inc. Press), 199-218.

Fu, C. C., Yang, T. F., Chen, C. H., Lee, L. C., Wu, Y. M., Liu, T. K., et al. (2017). Spatial and temporal anomalies of soil gas in northern Taiwan and its tectonic and seismic implications. J. Asian Earth Sci. 149, 64-77. doi:10.1016/j.jseaes. 2017.02.032

Hsu, C., and Wey, S. (1983). Structural geology in the Chiayi foothills, Taiwan. Pet. Geology. Taiwan 19, 17-28.

Hung, J. H., Wiltschko, D. V., Lin, H. C., Hickman, J. B., Fang, P., and Bock, Y. (1999). Structure and motion of the southwestern Taiwan fold and thrust belt. Terr. Atmos. Ocean. Sci. 10 (3), 543-568. doi:10.3319/tao.1999.10.3.543(t)

Igarashi, G., Saeki, S., Takahata, N., Sumikawa, K., Tasaka, S., Sasaki, Y., et al. (1995). Ground-water radon anomaly before the Kobe earthquake in Japan. Science 269 (5220), 60-61. doi:10.1126/science.269.5220.60
K.H. Chen for helping in the operation and maintenance of the monitoring station and preliminary data analysis. The TEC contribution number for this article is 00167 .

Kuo, M. C. T., Fan, K., Kuochen, H., and Chen, W. (2006). A mechanism for anomalous decline in radon precursory to an earthquake. Ground Water 44 (5), 642-647. doi:10.1111/j.1745-6584.2006.00219.x

Kuo, T., Su, C., Chang, C., Lin, C., Cheng, W., Liang, H., et al. (2010). Application of recurrent radon precursors for forecasting large earthquakes $(\mathrm{Mw}>6.0)$ near Antung, Taiwan. Radiat. Meas. 45 (9), 1049-1054. doi:10.1016/j.radmeas.2010. 08.009

Lai, W. C., Hsu, K. C., Shieh, C. L., Lee, Y. P., Chung, K. C., Koizumi, N., et al. (2010). Evaluation of the effects of ground shaking and static volumetric strain change on earthquake-related groundwater level changes in Taiwan. Earth Planets Space 62 (4), 391-400. doi:10.5047/eps.2009.12.008

Lin, C. W., Chang, W. C., Lu, S. T., Shih, T. S., and Huang, W. C. (2000). An introduction to the active faults of Taiwan. Spec. Publ. Cent. Geol. Surv. 13, 1-122. 2nd edition.(in Chinese).

Lin, C. W., Lu, S. T., Shih, T. S., Liu, Y. C., Lin, W. H., and Lin, Y. H. (2007). Active faults of southwestern Taiwan: explanatory text for the strip maps of active faults scale: 25000, Meishan fault. Spec. Publ. Cent. Geol. Surv. 17, 81-94.(in Chinese).

Lis, G., Wassenaar, L. I., and Hendry, M. J. (2008). High-precision laser spectroscopy $\mathrm{D} / \mathrm{H}$ and $18 \mathrm{O} / 16 \mathrm{O}$ measurements of microliter natural water samples. Anal. Chem. 80 (1), 287-293. doi:10.1021/ac701716q

Liu, K. K., Yui, T. F., Yeh, Y. H., Tsai, Y. B., and Teng, T. (1985). Variations of radon content in ground waters and possible correlation with seismic activities in northern Taiwan. Pure Appl. Geophys. 122 (2-4), 231-244. doi:10.1007/ bf00874596

Los Gatos Research Inc. (2008). Liquid-water isotope analyser, automated injection (Accessed August 18, 2008).

Mizota, C., and Kusakabe, M. (1994). Spatial distribution of $\delta \mathrm{D}-\delta^{18} \mathrm{O}$ values of surface and shallow groundwaters from Japan, South Korea and East China. Geochem. J. 28 (5), 387-410. doi:10.2343/geochemj.28.387

Onda, S., Sano, Y., Takahata, N., Kagoshima, T., Miyajima, T., Shibata, T., et al. (2018). Groundwater oxygen isotope anomaly before the M6.6 Tottori earthquake in Southwest Japan. Sci. Rep. 8 (1), 4800. doi:10.1038/s41598018-23303-8

Ono, T., Mori, T., and Tsunomori, F. (2020). High-frequency field auto-sampling of volcanic waters discharged near craters of active volcanoes. Bull. Volcanol. 82 (2), 16. doi:10.1007/s00445-020-1357-y

Orihara, Y., Kamogawa, M., and Nagao, T. (2014). Preseismic changes of the level and temperature of confined groundwater related to the 2011 Tohoku Earthquake. Sci. Rep. 4 (1), 6907. doi:10.1038/srep06907

O’Neil, J. R., and King, C. Y (1981). Variations in stable-isotope ratios of ground waters in seismically active regions of California. Geophys. Res. Lett. 8 (5), 429-432. doi:10.1029/gl008i005p00429

Peng, T. R., Wang, C. H., Huang, C. C., Fei, L. Y., Chen, C. T. A., and Hwong, J. L. (2010). Stable isotopic characteristic of Taiwan's precipitation: a case study of western Pacific monsoon region. Earth Planet. Sci. Lett. 289 (3, 4), 357-366. doi:10.1016/j.epsl.2009.11.024

Poreda, R., and Craig, H. (1989). Helium isotope ratios in Circum-Pacific volcanic arcs. Nature 338 (6215), 473-478. doi:10.1038/338473a0

Reddy, D., Nagabhushanam, P., and Sukhija, B. S. (2011). Earthquake (M5.1) induced hydrogeochemical and $\delta^{18} \mathrm{O}$ changes: validation of aquifer breachingMixing model in Koyna, India. Geophys. J. Int. 184 (1), 359-370. doi:10.1111/j. 1365-246X.2010.04838.x

Roeloff, E. (1988). Hydrologic precursors to earthquakes: a review. Pure Appl. Geophys. PAGEOPH 126 (2-4), 177-209. doi:10.1007/bf00878996

Sadovsky, M. A., Nersesov, I. L., Nigmatullaev, S. K., Latynina, L. A., Lukk, A. A., Semenov, A. N., et al. (1972). The processes preceding strong earthquakes in some regions of Middle Asia. Tectonophysics 14 (3, 4), 295-307. doi:10.1016/ 0040-1951(72)90078-9

Sano, Y., Takahata, N., Igarishi, G., Koizumi, N., and Sturchio, N. C. (1998). Helium degassing related to the Kobe earthquake. Chem. Geol. $150(1,2)$, 171-179. doi:10.1016/S0009-2541(98)00055-2 
Sano, Y., Takahata, N., Kagoshima, T., Shibata, T., Onoue, T., and Zhao, D. (2016). Groundwater helium anomaly reflects strain change during the 2016 Kumamoto earthquake in southwest Japan. Sci. Rep. 6 (1), 37939. doi:10. 1038/srep37939

Sano, Y., Kinoshita, N., Kagoshima, T., Takahata, N., Sakata, S., Toki, T., et al. (2017). Origin of methane-rich natural gas at the West Pacific convergent plate boundary. Sci. Rep. 7 (1), 15646. doi:10.1038/s41598-017-15959-5

Sano, Y., Onda, S., Kagoshima, T., Miyajima, T., Takahata, N., Shibata, T., et al. (2020). Groundwater oxygen anomaly related to the 2016 Kumamoto earthquake in Southwest Japan. Proc. Jpn. Acad. Ser. B Phys. Biol. Sci. 96 (7), 322-334. doi:10.2183/pjab.96.024

Sano, Y., and Wakita, H. (1985). Geographical distribution of ${ }^{3} \mathrm{He} /{ }^{4} \mathrm{He}$ ratios in Japan: implications for arc tectonics and incipient magmatism. J. Geophys. Res. 90 (B10), 8729-8741. doi:10.1029/jb090ib10p08729

Shih, R. C., Chen, P. H., Lu, M. T., and Chen, W. S. (2003). Earthquake geology investigation and the construction of the active faults database. Geophys. Invest. Projects Active Faults. Ann. Rep., Cent. Geol. Surv., Ministry Econ. Aff. Taipei, Taiwan, 218, (in Chinese).

Skelton, A., Andren, M., Kristmannsdottir, H., Stockmann, G., Morth, C. M., Sveinbjornsdottir, A., et al. (2014). Changes in groundwater chemistry before two consecutive earthquakes in Iceland. Nat. Geosci. 7 (10), 752-756. doi:10. $1038 /$ ngeo 2250

Song, S. R., Ku, W. Y., Chen, Y. L., Lin, Y. C., Liu, C. M., Kuo, L. W., et al. (2003). Groundwater chemical anomaly before and after the Chi-Chi earthquake in Taiwan. Terr. Atmos. Oceanic Sci. 14 (3), 311-320. doi:10.3319/tao.2003.14.3.311(t)

Song, S. R., Chen, Y. L., Liu, C. M., Ku, W. Y., Chen, H. F., Liu, Y. J., et al. (2005). Hydrochemical changes in spring waters in Taiwan: implications for evaluating sites for earthquake precursory monitoring. Terr. Atmos. Ocean. Sci. 16 (4), 745-762. doi:10.3319/tao.2005.16.4.745(gig)

Song, S. R., Ku, W. Y., Chen, Y. L., Liu, C. M., Chan, P. S., Chen, Y. G., et al. (2006). Hydrogeochemical anomalies in the springs of the Chiayi area in west-central Taiwan as likely precursors to earthquakes. Pure Appl. Geophys. 163, 675-691. doi:10.1007/s00024-006-0046-x

Sugisaki, R., and Sugiura, T. (1985). Geochemical indicator of tectonic stress resulting in an earthquake in central Japan, 1984. Science 229 (4719), 1261-1262. doi:10.1126/science.229.4719.1261

Sugisaki, R. (1978). Changing $\mathrm{He} / \mathrm{Ar}$ and $\mathrm{N}_{2} / \mathrm{Ar}$ ratios of fault air may be earthquake precursors. Nature 275 (5677), 209-211. doi:10.1038/275209a0

Sun, C. H., Chang, S. C., Kuo, C. L., Wu, J. C., Shao, P. H., and Oung, J. N. (2010). Origins of Taiwan's mud volcanoes: evidence from geochemistry. J. Asian Earth Sci. 37 (2), 105-116. doi:10.1016/j.jseaes.2009.02.007

Tryon, M., Brown, K., Dorman, L. R., and Sauter, A. (2001). A new benthic aqueous flux meter for very low to moderate discharge rates. Deep Sea Res. Part I Oceanogr. Res. Pap. 48 (9), 2121-2146. doi:10.1016/S0967-0637(01)00002-4

Wakita, H., Nakamura, Y., Notsu, K., Noguchi, M., and Asada, T. (1980). Radon anomaly: a possible precursor of the 1978 izu-oshima-kinkai earthquake. Science 207 (4433), 882-883. doi:10.1126/science.207.4433.882
Wang, C. H., Kuo, C. H., Peng, T. R., Chen, W. F., Liu, T. K., Chiang, C. J., et al. (2001). Isotope characteristics of Taiwan groundwaters. West. Pac. Earth Sci. 1 (4), 415-428.

Wang, C. Y., Cheng, I. H., Chin, C. V., and Yu, S. B. (2001). Coseismic hydrologic response of an alluvial fan to the 1999 Chi-Chi earthquake, Taiwan. Geology 29 (9), 831-834. doi:10.1130/0091-7613(2001)029<0831: CHROAA $>2.0 . \mathrm{CO} ; 2$

Weinlich, F. H. (2014). Carbon dioxide controlled earthquake distribution pattern in the NW Bohemian swarm earthquake region, western Eger Rift, Czech Republic-Gas migration in the crystalline basement. Geofluids 14 (2), 143-159. doi:10.1111/gfl.12058

Weiss, R. F. (1971). Solubility of helium and neon in water and seawater. J. Chem. Eng. Data 16 (2), 235-241. doi:10.1021/je60049a019

Yang, T. F., Chou, C. Y., Chen, C. H., Chyi, L. L., and Jiang, J. H. (2003). Exhalation of radon and its carrier gases in SW Taiwan. Radiat. Meas. 36 (1-6), 425-429. doi:10.1016/s1350-4487(03)00164-1

Yang, T. F., Yeh, G. H., Fu, C. C., Wang, C. C., Lan, T. F., Lee, H. F., et al. (2004). Composition and exhalation flux of gases from mud volcanoes in Taiwan. Environ. Geol. 46 (8), 1003-1011. doi:10.1007/s00254-004-1086-0

Yang, T. F., Walia, V., Chyi, L. L., Fu, C. C., Chen, C. H., Liu, T. K., et al. (2005). Variations of soil radon and thoron concentrations in a fault zone and prospective earthquakes in SW Taiwan. Radiat. Meas. 40 (2-6), 496-502. doi:10.1016/j.radmeas.2005.05.017

Yang, T. F., Fu, C. C., Walia, V., Chen, C. H., Chyi, L. L., Liu, T. K., et al. (2006). Seismo-geochemical variations in SW Taiwan: multi-parameter automatic gas monitoring results. Pure Appl. Geophys. 163 (4), 693-709. doi:10.1007/s00024006-0040-3

Yang, T. F. (2008). Recent progress in the application of gas geochemistry: examples from Taiwan and the 9th international gas geochemistry conference. Geofluids 8 (4), 219-229. doi:10.1111/j.1468-8123.2008.00232.x

Yu, S. B., Chen, H. Y., and Kuo, L. C. (1997). Velocity field of GPS stations in the Taiwan area. Tectonophysics 274 (1-3), 41-59. doi:10.1016/s0040-1951(96) 00297-1

Yu, S. B., and Chen, H. Y. (1998). Strain accumulation in southwestern Taiwan. Terr. Atmos. Ocean. Sci. 9 (1), 31-50. doi:10.3319/TAO.1998.9.1.31

Conflict of Interest: The authors declare that the research was conducted in the absence of any commercial or financial relationships that could be construed as a potential conflict of interest.

Copyright (c) $2021 \mathrm{Fu}, \mathrm{Lai}$, Yang, Hilton, Chen, Walia, Kumar and Lee. This is an open-access article distributed under the terms of the Creative Commons Attribution License (CC BY). The use, distribution or reproduction in other forums is permitted, provided the original author(s) and the copyright owner(s) are credited and that the original publication in this journal is cited, in accordance with accepted academic practice. No use, distribution or reproduction is permitted which does not comply with these terms. 